Post-print of Can. J. For. Res. 47: 371-381.

DOI: 10.1139/cjfr-2016-0203

\title{
Douglas-fir radial growth in interior British Columbia can be linked to long-term oscillations in Pacific and Atlantic sea surface temperatures
}

\author{
Yueh-Hsin $\mathrm{Lo}^{1,2}$, Juan A. Blanco ${ }^{2}$, Biing T. Guan ${ }^{1, *}$
}

${ }^{1}$ School of Forestry and Resource Conservation, National Taiwan University No. 1, Sec. 4, Roosevelt Road,

Taipei, 10617, Taiwan (R.O.C.).

${ }^{2}$ Departamento de Ciencias del Medio Natural, Universidad Pública de Navarra, Campus de Arrosadía,

Pamplona, Navarra, 31006, Spain.

E-mails:

Yueh-Hsin Lo: yuehhsin.lo@gmail.com

Juan A. Blanco: juan.blanco@unavarra.es

* Corresponding author: Biing T. Guan: $\underline{\text { btguan@ntu.edu.tw }}$ 


\begin{abstract}
A major problem in modern dendrochronology is that the methods traditionally used for linking tree ring growth data to climate records are not well suited to reconstructing low-frequency climatic variations. In this study, we explored the alternative Ensemble Empirical Mode Decomposition to detrend tree-ring records and to extract climate signals without removing low-frequency information. Tree cores of Pseudotsuga menziesii var. glauca (Mayr.) Franco were examined in a semi-arid forest in southern interior British Columbia, western Canada. Ring width data were decomposed into five oscillatory components (intrinsic mode functions, IMFs) of increasingly longer periodicities. IMF 1 was considered white noise, IMF 2 was used to create the first diameter growth index (DGI-1), IMF 3 and IMF 4 were combined to create the second diameter growth index (DGI-2), whereas IMF 5 and the residual term together were considered as the trend term. The highest significant cross-correlations between DGI-1 and the $\mathrm{NAO}_{\text {August }}, \mathrm{NIN} O 12_{\text {May }}$, and $\mathrm{PDO}_{\text {January }}$ indices were found at 1-year lags. DGI-2 had positive and persistent correlations with $\mathrm{NAO}_{\text {June }}$ and $\mathrm{PDO}_{\text {May }}$ at 0 to 3 years lags, and with $\mathrm{NAO}_{\text {May }}$ at 2 and 3 years lags. Our results indicate that periods of slow growth in the tree ring record matched periods of drought in the North American Pacific Northwest. Such water limiting conditions are likely caused by oscillatory patterns in the Pacific Ocean sea surface temperatures that influence precipitation in the Pacific Northwest. These drought events are likely exacerbated by changes in winter precipitation (snowpack) related to oscillations of the Atlantic Ocean sea surface temperatures, highlighting the ecological effects of both oceans on terrestrial ecosystems. Such relationships could not be easily found by traditional tree-ring analysis that remove some of the low-frequency signal, and therefore we suggest Ensemble Empirical Mode Decomposition as an additional tool to establishing tree growth-climate relationships.
\end{abstract}

Keywords: Growth-climate relationships; Ensemble Empirical Mode Decomposition (EEMD); Dendroclimatology, Decadal climate oscillations, Low-frequency climate oscillations. 


\section{Introduction}

A major problem in modern dendrochronology is that the methods traditionally used for linking tree ring growth data to climate records are not well suited to reconstructing low-frequency signals of climatic variability (Shi et al., 2012). However, quantifying such relationships is a key step for reconstructing past climate and for exploring ecosystem response to climate variability (Chhin et al., 2008). Therefore, alternative analytical tools are needed that allow for the study of the influences of global, low-frequency climate oscillations on ecological processes in forests around the world.

In the North American Pacific Northwest region (PNW), Watson and Luckman $(2001 ; 2005)$ have summarized the dendroclimatology research and reconstructed annual precipitation and past summer temperatures in the Canadian Rockies. Tree ring responses to climatic anomalies and insect outbreaks have been examined for the region (Zhang et al., 1999; Zhang et al., 2004). Bower et al. (2005) used ring attributes (width, density, and mass) and their relationships with soil moisture deficit during growing seasons to build a drought response coefficient for Douglas-fir (Pesudotsuga menziesii (Mirb.) Franco). Peterson and collaborators conducted a series of studies to examine the effects of climatic variability during the $20^{\text {th }}$ century on the growth of lodgepole pine (Pinus contorta Doug.) and Douglas-fir along an elevation gradient in the North Cascades of USA (Case and Peterson, 2005; Case and Peterson, 2007). Lo et al. (2010a; 2010b) found that lodgepole pine, Douglas-fir, and hybrid white spruce (Picea glauca x engelmannii) growth responses to climate were different depending on the biogeoclimatic zones where the trees grew in interior British Columbia (BC), Canada.

However, all the studies mentioned above explored the relationship between stem radial growth and relatively short climatic signals (e.g. different lags of monthly or yearly averages of temperature, precipitation, drought indices, etc.). Short-term weather patterns certainly influence vegetation growth, but the influence of longer-term climate variability has been more difficult to relate to tree growth. This could be problematic when studying global climate change, as we must consider the contributions from both natural and anthropogenic forcings at longer time scales (Huang and Wu, 2008; Wu et al., 2008).

At multi-annual scales, climate oscillations are related to changes in ocean temperatures (Hurrell, 1995). Changes in sea surface temperature (SST) are directly linked to changes in air temperature and precipitation 
patterns on land masses (Rodwell et al., 1999). Given the oceans' geographical complexity and interconnectivity, combined with the oceans' massive latent heat capacity, there are important lags and inertia in SST changes. Combined with the existence of global atmospheric wave-like patterns, several multi-year quasi-periodic oscillatory patterns have been identified in all of the oceans, such as the El NiñoSouthern Oscillation (ENSO), the Pacific Decadal Oscillation (PDO), and the North Atlantic Oscillation (NAO), among others. Previous studies based on tree ring chronologies from western North America have found significant relationships between tree ring width and PDO (Biodin et al., 2001; MacDonald and Case, 2005), using refinements of traditional dendroclimatological methods.

The current data analysis paradigm in dendroclimatology has two main components: detrending and time series analysis. Detrending is the key step in successfully separating the climatic signals and their effects on tree growth from the non-climatic growth trend (Fritts, 2001). Traditionally, detrending is accomplished by fitting an a priori chosen function to tree-ring series. The current paradigm has several limitations. First, external information is injected into the data during the detrending process by imposing a subjectively chosen function into the data series to remove the non-climatic, age-related growth trend. Second, to use the established time series analysis methods, the paradigm also assumes that the data are linear and stationary. However, most of the data in nature are neither linear nor stationary (Huang and Wu, 2008; Shih et al., 2014), and as a result potential valuable information could be removed by traditional detrending, particularly for changes in long time scales that could be related to the multiannual to multidecadal oscillation in climate. An alternative is ensemble empirical mode decomposition (EEMD), a method specially designed for analyzing non-linear and non-stationary data. As an improvement of empirical mode decomposition (EMD), it is an adaptive method based on and derived from the data set itself, and therefore it is highly efficient (Wu and Huang, 2009). From high to low frequencies, a time series is decomposed into a set of oscillatory components (the intrinsic mode functions, IMFs) and a residual term. Applied to dendrochronological data, the residual term captures the non-oscillatory trends in tree growth, such as the age trend (Zhang and Chen, 2016) and therefore no subjectively chosen functions are needed to capture the trend growth, whereas the IMFs indicate periodic influences on tree growth (Guan et al., 2012). However, the physical meaning of each 
IMF is not always clear. Detailed descriptions of EMD/EEMD can be found in Huang et al. (1998), Huang and $\mathrm{Wu}(2008)$, and $\mathrm{Wu}$ and Huang (2009).

EEMD is a technique developed in the last 20 years, with the works of Huang and collaborators (cited above) describe the theoretical advantages of EEMD over traditional time series analysis and its limitations, as well as its application in different technical fields. In dendrochronology, the practical advantages of EEMD versus traditional detrending techniques have already been explored (Fang et al., 2013; Zhang and Chen, 2016). Their results show that while the EEMD-generated chronologies were almost the same to the ones generated by traditional techniques, EEMD has better capacity to retain more low-frequency signal. EEMD has been applied to dendroclimatological studies to better explore the relationships between climate and tree growth or to isolate the growth trend (Zhang et al., 2008; Shi et al., 2012; Shi et al., 2014). Guan et al. (2012) used EEMD as a detrending method to preserve lower-frequency signals in a relatively short time series and was able to detect the influence of PDO on height growth of Taiwan spruce (Picea morrisonicola Hay.). Guan (2014) also applied EEMD to demonstrate the close correspondence between tree flowering phenology and weather records in Europe.

These cited works show the potential of EEMD as an complementary tool to explore ecological and particularly dendrochronological ecological time series. However, in our knowledge an assessment of how much temporal variability in tree growth at local scales can be related to low-frequency signals kept by EEMD is still missing from scientific literature. In addition, dendroclimatological studies usually leave an important part of the variance in tree ring data unexplained. Therefore, the objective of this research was to quantify the variability in tree-ring width series detrended with EEMD that can be explained by multi-annual quasi-periodic climate variations. To do so, we re-analyzed a tree-ring dataset previously studied by Lo et al. (2010b) with traditional dendroclimatological techniques, and estimated the influence of inter-annual to decadal climate variability on tree ring width using EEMD as the detrending method.

We applied EEMD to Lo et al.'s (2010b) data from Douglas-fir forests in interior British Columbia, the same dendrochronological data described in Lo et al. (2010b). These forests were selected as these are found in a dry climate and therefore better suited to express inter-annual changes in growing conditions due to climate variability in their tree ring annual growth. Additionally, there is 
a wealth of information on Douglas-fir, helping to understand the ecophysiological influences of climate on annual tree growth, and particularly previous studies in the target forests (Lo et al. 2010a, b) also facilitate understanding the ecophysiology of thes eforests and allow for comparison between detrending approached. Finally, previous research has shown that Douglas fir is the most climate sensitive species in the study region (Case and Peterson 2005, Lo et al. 2010b), therefore making it the most suitable species to try a new technique to look for influences of climate on tree growth. Revisiting Lo et al. (2010b) tree ring data allowed for the comparison in variability explained by traditional and EEMD methods. Lo et al. (2010b) presented a multivariate model which significantly explained $43 \%$ of the annual variation in Douglas-fir tree ring width at an arid site in interior BC by including annual precipitation, May precipitation, previous July temperature, and July potential evapotranspiration. Monthly PDO values were also included in the same analysis, but not detected as significantly correlated with tree ring width. We hypothesized that part of the previously unexplained variance by Lo et al. (2010b) in Douglas-fir annual ring width was significantly influenced by quasi-periodic oscillations in SST, but the removal of low-frequency signals by traditional detrending (i.e. using exponential or spline methods) could have hidden significant relationships with low-frequency climate oscillations.

\section{Material and Methods}

\section{Study site}

The study site was located in Tolko Industries Ltd's Tree Farm License 49 in the Okanagan Valley, near Westwold $\left(50^{\circ} 22^{\prime} \mathrm{N}, 119^{\circ} 56^{\prime} \mathrm{W}, 1130 \mathrm{~m}\right.$ a.s.l., Fig. 1). Mean annual precipitation in the area is $352.3 \mathrm{~mm}$, and mean annual temperature is $6.1{ }^{\circ} \mathrm{C}$, with mean July temperature $19.1^{\circ} \mathrm{C}$ and mean December temperature $-2.9^{\circ} \mathrm{C}$ (Fig. 2). The average temperature is below $0^{\circ} \mathrm{C}$ for 2 to 5 months and above $10^{\circ} \mathrm{C}$ for 3 to 5 months. Twenty to $50 \%$ of the precipitation falls as snow (Hope et al., 1991). Substantial growing season moisture deficits are common (Fig. 1). The study was placed in the biogeoclimatic zone of Interior Douglas-fir (IDF), in the IDFdk1 variant (dry and cool) (Pojar et al., 1987). The IDF zone dominates the low- to mid-elevation landscape of south-central interior BC at altitudes of 600 to 1,400 m a.s.l. This ecological zone also extends south into Washington, Oregon, Idaho, and Montana, and east into Alberta. The IDF zone has a continental 
climate characterized by warm, dry summers, a fairly long growing season, and cool winters. The main factor controlling the climate is the rain shadow created in the lee of topographic barriers (the Coast, Cascade, and Columbia mountains) to the prevailing easterly flowing air. The most abundant tree species is interior Douglas-fir. Other species present are lodgepole pine and hybrid white spruce. Douglas-fir is also the most sensitive one among the three species to climate variability (Case and Peterson, 2005; Lo et al., 2010a; Lo et al., 2010b), and therefore cores from this species were selected for the study.

\section{Diameter growth data}

Data used in this study were a subset of the tree growth analysis data collected in 2003 (Lo et al., 2011). Sampled trees were deliberately located on zonal or mesic sites (but still in an arid climate), in which soil moisture experienced by trees is dominated by local precipitation and climate-induced water balance. This strategy was adopted in order to characterize the response of the majority of the tree populations within the IDF zone, and not just a selection of trees on the driest end of the soil moisture gradient. The average DBH of the selected trees was $53.9 \pm 9.2$ (mean \pm s.e.) $\mathrm{cm}$ and the average height was $30.4 \pm 6.1 \mathrm{~m}$. One core per tree was taken at breast height $(\sim 1.30 \mathrm{~m})$. Cores were air-dried, soaked in an acetone solution for 24 hours to remove the extractives, and then air-dried again. Cores of poor quality (e.g., fragmented, rotted, or not cross-datable) were excluded. Annual tree ring widths were measured in an X-ray densitometer (model QTRS-01X, QMS, Quintek Measurement Sys. Inc., Knoxville, Tennessee, U.S.A.), and visual crossdating was confirmed with the COFECHA software (Grissino-Mayer, 2001). Cores with correlation with the master series lower than 0.45 were removed from the analysis. As a result, 40 cores with first ring dated in 1900 or earlier were used, to create a tree-ring chronology spanning from 1788 to 2003 . Average annual tree ring width series was used for subsequent analyses.

As high quality and reliable climate data from western North American weather stations are available only since 1950, we limited our tree ring width data series to the period 1950-2003 (Fig. 2). For this period, research suggests that ENSO can be related to warmer drier (cooler wetter) winters in PNW during the El Niño (La Niña) phase, with approximately a 6-year cycle (Redmond and Koch, 1991; McCabe and Dettinger, 1999; Mote et al., 1999). On the other hand, PDO also affects PNW's local climate, but at lower frequencies 
(20-40 years), and with a modulating effect on ENSO. The positive (negative) phase of the PDO is associated with warmer drier (cooler wetter) winters and it has been related to fire recurrence (Hessl et al., 2004). Finally, a NAO positive phase with strong westerlies has been linked to reduced winter severity (Thompson and Wallace, 2001) and Douglas-fir defoliation in PNW (Nott et al., 2002).

\section{Construction of diameter growth indices}

The objective of EMD is to decompose a time series into a small and finite number of IMFs and a residual (trend) component (Huang et al., 1998; Huang and Wu, 2008). The method has been further refined to alleviate the signal intermittence problem, creating the EEMD approach (Wu and Huang, 2009), which is a Monte Carlo process in which zero-mean Gaussian white noise is added to each EMD decomposition to achieve better signal separation. In essence, EEMD seeks to extract oscillatory components embedded in a signal series, going from high to low frequency until it cannot find one. At that point, the residual should be constant, monotonic, or with only one extremum. Usually, the residual or a combination of the residual with either the last one or two IMFs will constitute a growth trend (Guan et al. 2012). Thus, detrending is done in a posteriori and, to certain extent, automatic fashion. Because EMD/EEMD decomposes time series based on local behaviors and in a sequential manner, there is no need to assume either linearity or stationarity in data. It also does not require an a priori structure about the trend, as it is derived intrinsically and adaptively (Wu et al., 2007). In addition, because there is no tree-ring data standardization or transformation when using EEMD, IMFs are in their natural measuring unit ( $\mathrm{mm}$ in this case). Therefore, influences of climate variables on radial growth can be directly quantified, an advantage compared to traditional detrending methods. As and additional advantage, by no needing previous standardization, the issues of using ring width as a proxy of radial growth rather than stem basal area increment (Biondi and Qeadan, 2008) are avoided. These properties make EEMD an ideal tool for separating oscillatory components from the trend (Guan, 2014).

The decomposition was based on the EEMD MATLAB codes provided by the Research Center for Adaptive Data Analysis of the National Central University of Taiwan (available at http://rcada.ncu.edu.tw/research1 clip_program.htm). EEMD run comprised 1,000 EMD runs. The standard deviation of the introduced Gaussian white noise was 0.01 of that of the average annual tree ring width series. 
Five IMFs and a residual term were extracted from the tree ring width series. Basic spectral analysis (Legendre and Legendre, 1998) for each IMF was carried out previously to test for correlations among the IMFs in order to select the IMFs for the creation of diameter growth indices (DGIs)..

The first IMF contained the short frequency signal (periodicity $\leq 1$ year), and it was not significantly different from white noise as tested by both Fisher's Kappa ( $p=0.257)$ and Bartlett's K-S $(p=0.163)$ statistics (Zuur et al., 2007). The fifth IMF and the residual term were significantly correlated $(r=0.260, p=$ 0.049). Therefore, we considered them as the trend component in the data. We also found a significant correlation between the third and fourth IMFs $(r=-0.394, p<0.001)$, but no correlations among them and the second IMF. Therefore, we created two DGIs, with DGI-1 being the second IMF and DGI-2 being the sum of the third and fourth IMFs (Fig. 3). The correlation between DGI-1 and DGI-2 was not significant $(r=$ $0.066, p=0.653$ ). However, both indices significantly correlated with the average annual ring width (DGI-1 $r=0.450, p<0.001$; DGI- $r=0.500, p<0.001)$. These facts indicated that the DGIs isolated different oscillatory components form the original tree ring width series. DGI-1 contained oscillations with periodicities between 5 and 9 years, with the most significant periodicity at 8 years. The periodicities in DGI-2 ranged from 8 to 14 years, with the last value being the most significant period.

\section{Data analysis}

\section{Temporal features of local climate and relationships with global climate}

To have a general characterization of the oscillatory properties of the local climate, spectral analysis (Legendre and Legendre, 1998) of Westwold's average annual temperature $\left(\mathrm{T}_{\text {avg }}\right)$ and annual accumulated precipitation $\left(\mathrm{P}_{\mathrm{ann}}\right)$ were carried out To identify the responses of local weather to the changes in the Atlantic and Pacific oceans, we used cross-correlation to correlate Westwold's weather records with the annually averaged NAO (Trouet et al., 2009), NIÑO12 $\left(0^{\circ} \mathrm{N}-10^{\circ} \mathrm{S}, 90^{\circ} \mathrm{W}-80^{\circ} \mathrm{W}\right)$, NIÑO34 $\left(5^{\circ} \mathrm{N}-5^{\circ} \mathrm{S}, 170^{\circ} \mathrm{W}-120^{\circ} \mathrm{W}\right)$ (Climate Prediction Center, NOAA, http://www.cpc.noaa.gov/data/indices), and PDO (http://jisao.washington.edu/pdo). As no significant relationships were found with NIÑO34, this index was discarded for additional analyses (Fig. 2). 
Guided by the results, we further explored the relationships between monthly temperature and precipitation data with the detrended HadISST1 dataset (Rayner et al. 2003), which is a reconstructed $1^{\circ} \times 1^{\circ}$ SST field, grouped into different seasons. We performed spatiotemporal correlations between each climate variable and the gridded SST field via the Royal Netherlands Meteorological Institute, Climate Explorer website (https://climexp.knmi.nl/) (Trouet and Van Oldenborgh, 2013).

\section{Correlations between growth indices and local climate}

First, we tested for similitudes between the spectra of average annual tree ring width and the $\mathrm{T}_{\text {avg }}$ and $\mathrm{P}_{\mathrm{ann}}$ series of Westwold by using a multi-taper version of magnitude squared spectral coherence (Mann and Lees, 1996; Wright et al., 2015), using the R package multitaper (Rahim, 2014). We used three $2 \pi$ tapers and a red noise background null hypothesis as recommended for instrumental climate records (Ghil et al., 2002).

We then examined the relationships between DGIs and Westwold's intra-annual climate data, corrected for the study sites (Lo et al., 2011). The climate variables studied were average May temperature and accumulated precipitation during the growing (frost-free) season from May to August. These variables were identified by Lo et al. (2010b) as the most influential in the short-term on interior Douglas-fir diameter growth at this site. The cross-correlations between these two variables and the DGIs were examined at various time lags, with the climate variables leading. Growing season precipitation was prewhitened before applying the correlation functions. For each DGI, only the highest correlation was retained.

\section{Correlations between growth indices and global climate}

We cross-correlated DGIs with monthly and seasonal NAO, NIÑO12, and PDO indices. Guided by the results, we then correlated the DGIs with the detrended HadISST1. Finally, we linked the precipitation of the months with the highest cross-correlations to the monthly NAO, NIÑO12, and PDO values between 1950 and 2003 by finding the periods with the most significant correlations, up to a three-year lag with the climate indices leading. Before carrying out all cross-correlations between DGIs and climate variables, outliers (identified by Mahalanobis`d distance) were removed, typically 0-2 data per analysis. Residuals’ normality (Kolmogorov-Smirnoff test) and homogeneity of variances (Spearman's test) were tested. 
To account for autocorrelation in the time series, one way is to adjust for the loss of degrees of freedom. Therefore, we estimated the effective degrees of freedom (edf) of the correlation based on the equation $e d f=$ $n\left(1-r_{1} r_{2}\right) /\left(1+r_{1} r_{2}\right)$, where $n$ is the number of observations, and $r_{1}$ and $r_{2}$ are the $1^{\text {st }}$-order autocorrelation coefficients of the two trends (Dawdy and Matalas, 1964). The tests of significance for the Pearson's correlation coefficients $(r)$ were based on the edf. We performed the correlations between each DGI and the gridded SST field via the Climate Explorer website (see Guan et al., 2012; Trouet and Van Oldenborgh, 2013; and references therein for detailed description of this procedure).

Finally, to evaluate the influences of climate oscillations on diameter growth, we started by identifying the lags with the highest cross-correlations between the mean annual diameter growth and the monthly NAO, PDO and NINOO12 anomaly indices with the indices leading for the lags identified previously. We then fitted a least square regression model to estimate the marginal effects of the identified oceanic indexes and their interactions on mean annual diameter growth, with appropriate leads in the independent variables. Residuals were tested for normality, homogeneity of variances, and independence (Kolmogorov-Smirnoff test, Spearman test, and Durbin-Watson test, respectively). All data analyses were conducted using the JMP 12 statistical package (SAS, Cary, NC.).

\section{Results}

\section{Temporal features of local climate and relationships with global climate}

The periodicity of both Westwold's $\mathrm{T}_{\mathrm{avg}}$ and $\mathrm{P}_{\mathrm{ann}}$ ranged between 2 and 14 years, with the most significant periodicity at 4.3 years for $\mathrm{T}_{\text {avg }}$ and at 6 years for $\mathrm{P}_{\text {ann }}$. Moderate but significant positive correlations were found between $\mathrm{T}_{\text {avg }}$ and current year PDO $(r=0.408, p=0.002)$, previous year NIÑO12 $(r$ $=0.367, p=0.006)$, and current year NAO $(r=0.284, p=0.037)$. As for $\mathrm{P}_{\mathrm{ann}}$, significant positive correlations were found with PDO (the strongest at a 2-year lag, $r=0.498, p<0.001$ ). No significant correlations were found between $\mathrm{P}_{\mathrm{ann}}$ and NIÑO12 or NAO at any lag. Such results supported the graphical similarity between Westwold's climate (particularly $\mathrm{P}_{\mathrm{ann}}$ ) and global climate indices (especially PDO) (Fig. 2). 
Spring (March to May) mean temperature and precipitation at Westwold were positively correlated with western and tropical Pacific Ocean SST of the current year, the areas of influence of ENSO (Fig. 4a, 4b), whereas summer mean temperature (July to September) was negatively correlated with north Atlantic Ocean SST of current year (Fig. 4c). Summer precipitation at Westwold was positively correlated with western north Pacific and eastern north Atlantic SST, the area of influence of NAO (Fig. 4d).

Correlations between growing season precipitation and PDO and NAO were significant at a lag of two years for both indices (with PDO, $r=0.478, p<0.001$; with NAO, $r=0.276, p=0.042$ ), suggesting that warmer northern Pacific or Atlantic oceans increased precipitation in interior British Columbia two years later. No significant correlation was found with the NIÑO12 index.

\section{Correlations between growth indices and local climate}

Moderate similitudes between frequency spectra (above $90 \%$ significance level) were found between average tree ring width and $\mathrm{T}_{\text {avg }}$ (magnitude squared coherence 0.55 ) for periodicities of $4-5$ years (in the range of ENSO events), and between average tree ring and $\mathrm{P}_{\mathrm{ann}}$ (magnitude squared coherence 0.46) for periodicities of 12.5-16.5 years (in the range of the interdecadal components of the PDO and NAO events). Such similitudes between tree ring width and climate signals were also expressed by the two DGIs, which represented diameter growth signals of different frequencies, reflecting the influences of both local climate and endogenous processes. No significant correlations were found between May temperature and both DGIs, neither between DGI-1 and growing season precipitation. However, the significant correlation $(r=0.479, p$ $<0.001$ ) between DGI-2 and growing season precipitation (May to August) showed that growing season precipitation during the current year had the strongest positive effect on current year's growth, reflecting the influence of available water on tree reserves and therefore on current tree ring growth.

\section{Correlations between growth indices and global climate}

The highest significant cross-correlation between DGI-1 and the $\mathrm{NAO}_{\text {Aug }}$ and NINOO12 $2_{\text {May }}$ indices were found for 1-year lags (both positive correlations), respectively (Fig. 5 top). DGI-1 was also negatively 
correlated with three-years-before spring SST in the central Pacific (the area of influence of NIÑO12, Fig. 6a). The most significant negative cross-correlation with the PDO index was found at 1-year lag (Fig. 5 top). The graphical resemblance between DGI-2 and PDO index was noticeable (Figs. 2 and 3), resulting in strong positive and persistent correlations between both variables at lags 0 to 3 years. Moderate significant negative cross-correlations were also found for $\mathrm{NAO}_{\text {May }}$ and $\mathrm{NAO}_{\mathrm{June}}$, with the highest values for 3-year and 1-year lags, respectively, but there were no significant cross-correlations with NIÑO12 (Fig. 5 bottom). DGI-2 was correlated negatively with current year growing season SST in the central northern Pacific and positively in the central northern Atlantic (the influential areas of PDO and NAO, respectively, Fig. 6b). Correlations of DGIs with seasonal indices were of lower magnitude than those for individual months (data not shown).

Our cross-correlation results suggested that the strongest relationships between the mean annual ring width and the three oceanic indices occurred with 1-year lagged NIÑO12, 1 to 3-year lagged NAO, and 3-year lagged PDO. The regression model showed 2-year lagged $\mathrm{NAO}_{\mathrm{Aug}}, 3$-year lagged $\mathrm{PDO}_{\mathrm{May}}$, and previous year NIÑO12 ${ }_{\text {March }}$ as significant factors, as well as a significant interaction between previous year $\mathrm{NINO} 12_{\text {Sep }}$ and 2-year lagged $\mathrm{NAO}_{\text {Aug }}$ indices. All the factors together explained approximately $41 \%$ of the variance $\left(\mathrm{R}^{2}=0.469, \mathrm{R}_{\text {adj }}^{2}=0.408, \mathrm{RMSE}=0.140, n=49, p<0.001\right)$.

\section{Discussion}

\section{Relationships between local climate variables and ENSO, PDO, and NAO}

Our results show that natural SST variability from both the northern Pacific (PDO) and the northern Atlantic (NAO) had significant correlations with local precipitation variables in Westwold, although correlations with PDO were stronger than with the NAO. A moderate influence of the Pacific SST variability on Westwold's climate is expected. However, the correlation between the Atlantic SST variability and local climate does come as a surprise. The topographical position of the study site (in the trench between the Coastal and Rocky Mountains and near the Okanagan Lake, a $351 \mathrm{~km}^{2}$ water body) has also likely influenced the local climate, probably modulating the local responses to large scale atmospheric-oceanic circulations (Lo et al., 2010a; Lo et al., 2011). 
Although the correlations were moderate, they are in the line of previous research done at continental scales. Thompson and Wallace (2001) showed the influence that the Atlantic Ocean SST oscillations can have influences beyond its region, particularly in the northern Pacific basin and the PNW. McCabe et al. (2004) also showed how a large part of the multidecadal drought frequency in the USA can be explained by PDO and Atlantic Multidecadal Oscillation combined. Similarly, Biondi et al. (2001) and MacDonald and Case (2005), using tree ring chronologies from Alberta to Baja California have shown the influence of PDO on tree radial growth in Pacific North America. More recently, Folland et al. (2009) have shown significant correlations between NAO and atmospheric pressure and precipitation over Pacific North America.

Mechanisms have been proposed to explain the influences of both oceans on the climate of interior BC. Swings from one phase to another phase can produce large changes in surface air temperature, winds, storminess, and precipitation over the Atlantic as well as the adjacent continents (Ambaum et al., 2001; Hurrell and Deser, 2009), and be partially transferred through the Arctic Ocean to the northern Pacific Ocean (Okumura et al., 2009). The NAO also affects oceans through changes in heat content, gyre circulations, mixed layer depth, salinity, high latitude deep water formation, and sea ice cover. Such a relationship between PNW precipitation and NAO (Dickson et al., 2000) could become important in the future, because as evidence mounts on the influence of human activity on sea-level atmospheric pressure, NAO is probably going to increase its intensity with climate change, affecting more the northern Pacific region (Gillett et al., 2003).

Some of the ecological consequences of such teleconnections on terrestrial ecosystems in PNW have been described before. Kushnir et al. (2010) showed evidence of correlation between warm tropical North Atlantic SST variability and North American droughts, particularly in the western coast. They argued that, although SSTs in the Pacific Ocean are related to inter-annual variability of precipitation in North America, at decadal time scales Atlantic SSTs are the modulating factor. Such a phenomenon can also be seen in our results, which indicates how the combination of warm tropical North Atlantic and warm equatorial Pacific SSTs were related to growing season droughts in Westwold with a lag of 1 year. Field correlation maps between local precipitation and HadlSST1 exhibited a PDO-like pattern (Figs. 4b, 4d), even though 
precipitation is more affected by the local topography than the global atmosphere system (Redmond and Koch, 1991; Burton et al., 2008).

On the other hand, ENSO seems to have a less direct relationship with local climate than PDO or NAO. This is different from previous studies on the western USA, where a strong connection between ENSO and drought has been reported (Cook et al., 2007). This lack of direct influence could be due to the geographic position of Westwold (Fig. 1), which is more northern than most of the sites studied in western USA, and to its local topography, as mentioned earlier. Based on the location for which different ENSO indices can be calculated, NIÑO12 is closer to the study place (Allan et al., 1996), and this may explain the detection of significant correlations with DGI-1.

It has been reported that cold ENSO years do not affect North American precipitation as severely as PDO when combined with cold north Atlantic conditions (Kushnir et al., 2010; Feng et al., 2011). Such a connection may explain the significant interaction between NAO and NIÑO12 indices found in our interior Douglas-fir tree ring records. Another explanation of this interaction could be the reported relationship between cold tropical Pacific SST, warm North Atlantic SST, and droughts in western North America (Feng et al., 2011). In addition, it is reasonable to expect lower influence of ENSO in our sites, as ENSO usually starts from the equatorial region while the PDO affects the whole northern Pacific Ocean region (Kaplan et al., 1998; Bond and Harrison, 2000). PDO has also been shown to have a modulating effect on ENSO (Hu et al., 2011). However, it is important to point out that ENSO still has an important effect on Westwold precipitation, but through its interaction with NAO.

\section{Relationships between DGIs and local climate variables}

Tree growth is influenced by the environmental conditions surrounding trees during cell division, expansion, and growth. Therefore, if local climate reflects global climatic oscillation as discussed above, then local trees will likely respond to these changes. Previous studies on the Canadian Coastal Cordillera have found evidences of PDO influencing Douglas-fir radial growth (Larocque and Smith, 2005). Also, Nott et al. (2002) reported cycles of defoliation in Douglas-fir forests in interior BC synchronized with changes in $\mathrm{NAO}$, and they attributed such changes to the cyclic changes in defoliator populations as winter conditions 
were affected by NAO. Similarly, Lo et al. (2010b), using traditional dendrochronology techniques, found that interior Douglas-fir secondary growth was significantly related to spring PDO values at a site nearby but higher in altitude to the one used here.

The results reported here indicate that such a relationship can be further extended to several years prior to current growth season. In addition, the influence Atlantic SST's variability on Douglas-fir radial growth has been detected for the first time in interior BC. A well-defined storm track connects the North Pacific and North Atlantic basins, being its intensity and position influenced by NAO (Hurrell and Deser, 2009), and growing season precipitation in the Okanagan Valley is strongly affected by storms (Swain and Eng, 1982). As soil moisture during the growing season is used by Douglas-fir for diameter and stem elongation (Krueger and Trappe, 1967), the role of PDO and NAO on drought in the Okanagan Valley may have conditioned tree secondary growth. The synchrony between climate indices and water limiting conditions, however, is the opposite in the PNW to the more widely studied in the North American Southwest (McCabe et al., 2004; MacDonald and Case, 2005).

Lags in the influences of climate indices and diameter growth can arise from a combination of climatic and endogenous factors. First, changes in winter and summer SST can affect precipitation on continental masses up to two years later. Second, reduced summer soil moisture can make the North America jet stream to shift northwards, reducing precipitation and extending drought conditions into autumn and winter (Oglesby and Erickson, 1989). Third, water availability in western Canada often depends on snow melting (Perez-Valdivia and Sauchyn, 2011). Both NAO and PDO have been related to snowpack in western Canada (Moore and McKendry, 1996; Mote, 2006). Soil moisture from snowmelt has been linked to winter sugar production and spring root elongation (Krueger and Trappe, 1967; Lo et al., 2010b). Another ecophysiological factor to take into account is needle life span. The flush of needles produced during years with high water availability can enhance photosynthesis activity and secondary growth during their life span. As needles in Douglas-fir typically last 6-8 years (Balster and Marshall, 2000), favorable soil moisture conditions can extend their influence on tree growth for several years. All these factors together could explain the autocorrelations and lags up to 3 years in the cross-correlations observed in our results (Fritts 2001). 
Using EEMD to analyze tree-ring data enabled us to detect significant correlations between interior Douglas-fir ring width and PDO, NAO, and ENSO, which Lo et al. (2010b) were unable to detect using the traditional dendroclimatological techniques. Their study explained a maximum of $43 \%$ of the ring width variability based on short-term (annual, seasonal or monthly) variables such as temperature, precipitations or degree-days. Such variables are directly affected by short-term variations (day-night cycle, seasonal cycle, convective clouds, storm fronts, heat waves, etc.) or by local features (topography, large water bodies, vegetation, etc.) (Lo et al., 2010a).

On the other hand, phenomena of quasi-periodic climate variations are by definition long-term variations in SST and sea level atmospheric pressure (Guan et al., 2012). In our present work, PDO, NAO, and ENSO combined were able to explain about $41 \%$ of the variability. Multiannual to multidecadal variations in these global climate indices were not included in the previous analysis by Lo et al. (2010b). Therefore, we consider that most of the variability explained in the results presented here could correspond to variability not explained before with the classical detrending methods. This fact would support our initial hypothesis that some of the previously unexplained variability in tree ring width records may be related to multi-annual to multi-decadal global events such as changes in oceanic SST's and atmospheric pressure.

\section{Conclusions}

This research reports the first evidence of the combined influence of both Atlantic and Pacific SST variability on tree ring width in interior BC. Although more work is needed to understand the biological meaning of the oscillatory components (IMFs), or the issues related to the type of data used to characterise stem radial growth (ring width, basal stem area, etc.), the high potential of using EEMD is demonstrated by the correlations found between IMFs and climate variables, which are similar or higher than the ones obtained using the traditional dendrochronological techniques. Our results also show that complex large-scale phenomena can have important influences in tree growth at local scales. Consequently, forecasting of potential effects of climate variability on tree growth should incorporate detailed large and small-scale analysis of climate, whenever possible. 


\section{Acknowledgements}

Funding for collecting tree cores was provided by the Sustainable Forest Management Network of Canada (SFN Network), through the project entitled "Modelling Stand Level Response of Montane Spruce Forests on TFL 49 to Intensification of Management" granted to J.P. (Hamish) Kimmins, University of British Columbia (SFM Network ref.: kimminshmode8). Yueh-Hsin Lo was supported by a grant from the Taiwan National Science Council (NSC 97-2313-B-002-041-MY3). Juan A. Blanco was supported by grants from the Spanish Ministry of Economy and Competitiveness (AGL2012-33465), a Marie Curie Action fellowship from the European Commission (CIG-2012-326718-ECOPYREN3), and a Campus Iberus grant for mobility of research staff. B.T. Guan was supported by grants from the Taiwan National Science Council (NSC 100-2313-B-002-027 and NSC 101-2313-B-002-015-MY3). The funding agencies were not involved in the study design, data collection, analysis and interpretation, or writing and deciding to submit this paper for publication.

\section{References:}

Allan, R., Lindesay, J. and Parker, D., 1996. El Nino: Southern oscillation and climatic variability. CSIRO.-Collingood, Victoria, Australia., 416 pp.

Ambaum, M.H.P., Hoskins, B.J. and Stephenson, D.B., 2001. Arctic oscillation or North Atlantic oscillation? Journal of Climate, 14(16): 3495-3507.

Balster, N.J. and Marshall, J.D., 2000. Decreased needle longevity of fertilized Douglas-fir and grand fir in the northern Rockies. Tree Physiology, 20(17): 1191-1197.

Biondi, F., Gershunov, A. and Cayan D. R. 2001. North Pacific decadal climate variability since 1661, Journal of Climate, 14, 5-10.

Biondi, F. and Qeadan F., 2008. A theory-driven approach to tree-ring standardization: defining the biological trend from expected basal area increment. Tree Ring Research 64(2): 81-96.

Bond, N.A. and Harrison, D.E., 2000. The Pacific decadal oscillation, air-sea interaction and central north Pacific winter atmospheric regimes. Geophysical Research Letters, 27(5): 731-734.

Bower, A.D., Adams, W.T., Birkes, D. and Nalle, D., 2005. Response of annual growth ring components to soil moisture deficit in young, plantation-grown Douglas-fir in coastal British Columbia. Canadian Journal of Forest Research, 35(10): 2491-2499.

Burton, A., Kilsby, C.G., Fowler, H.J., Cowpertwait, P.S.P. and O'Connell, P.E., 2008. RainSim: A spatial-temporal stochastic rainfall modelling system. Environmental Modelling \& Software, 23(12): 1356-1369.

Case, M.J. and Peterson, D.L., 2005. Fine-scale variability in growth-climate relationships of Douglas-fir, North Cascade Range, Washington. Canadian Journal of Forest Research, 35(11): 2743-2755. 
Case, M.J. and Peterson, D.L., 2007. Growth-climate relations of lodgepole pine in the North Cascades National Park, Washington. Northwest Science, 81(1): 62-75.

Chhin, S., Hogg, E.H., Lieffers, V.J. and Huang, S., 2008. Potential effects of climate change on the growth of lodgepole pine across diameter size classes and ecological regions. Forest Ecology and Management, 256(10): 1692-1703.

Chiesi, M. et al., 2002. Calibration and application of FOREST-BGC in a Mediterranean area by the use of conventional and remote sensing data. Ecological Modelling, 154(3): 251-262.

Cook, E.R., Seager, R., Cane, M.A. and Stahle, D.W., 2007. North American drought: Reconstructions, causes, and consequences. Earth-Science Reviews, 81(1-2): 93-134.

Dawdy, D.R. and Matalas, N.C., 1964. Statistical and probability analysis of hydrologic data, Part III: Analysis of variance, covariance and time series. In: V.T. Chow (Editor), Handbook of Applied Hydrology, A compendium of Water-Resources Technology. McGraw-Hill, New York, pp. 8.68-8.90.

Dickson, R.R. et al., 2000. The Arctic Ocean response to the North Atlantic oscillation. Journal of Climate, 13(15): 2671-2696.

Fang, K. et al., 2013. Precipitation over the past four centuries in the Dieshan Mountains as inferred from tree rings: An introduction to an HHT-based method. Global and Planetary Change, 107: 109-118.

Feng, S., Hu, Q. and Oglesby, R., 2011. Influence of Atlantic sea surface temperatures on persistent drought in North America. Climate Dynamics, 37(3-4): 569-586.

Folland, C.K. et al., 2009. The Summer North Atlantic Oscillation: Past, Present, and Future. Journal of Climate, 22(5): 1082-1103.

Fritts, H.C., 2001. Tree Rings and Climate. The Blackburn Press. , Caldwell, New Jersey, 567 pp.

Ghil, M., Allen, M.R., Dettinger, M.D., Ide, K., Kondrashov, D., Mann, M. E., Robertson, A. W., Saunders, A., Tian, Y., Varadi, F. and Yiou, P., 2002. Advanced spectral methods for climatic time series. Reviews of Geophysics, 40(1): 31-41.

Gillett, N.P., Zwiers, F.W., Weaver, A.J. and Stott, P.A., 2003. Detection of human influence on sea-level pressure. Nature, 422(6929): 292-294.

Grissino-Mayer, H.D., 2001. Evaluating Crossdating Accuracy: A Manual and Tutorial for the Computer Program COFECHA. Tree-Ring Research, 57(2): 205-221.

Guan, B.T., 2014. Ensemble empirical mode decomposition for analyzing phenological responses to warming. Agricultural and Forest Meteorology, 194: 1-7.

Guan, B.T., Wright, W.E., Chung, C.-H. and Chang, S.-T., 2012. ENSO and PDO strongly influence Taiwan spruce height growth. Forest Ecology and Management, 267: 50-57.

Hessl, A.E., McKenzie, D. and Schellhaas, R., 2004. Drought and Pacific Decadal Oscillation linked to fire occurrence in the inland Pacific Northwest. Ecological Applications, 14(2): 425-442.

Hope, G.D. et al., 1991. Interior Douglas fir zone. In: D. Meidinger and J. Pojar (Editors), Ecosystems of British Columbia, B.C. Ministry of Forests, Victoria, pp. 153-166.

Hu, Q., Feng, S. and Oglesby, R.J., 2011. Variations in North American Summer Precipitation Driven by the Atlantic Multidecadal Oscillation. Journal of Climate, 24(21): 5555-5570. 
Huang, N.E. et al., 1998. The empirical mode decomposition and the Hilbert spectrum for nonlinear and non-stationary time series analysis. Proceedings of the Royal Society a-Mathematical Physical and Engineering Sciences, 454(1971): 903-995.

Huang, N.E. and Wu, Z., 2008. A review on Hilbert-Huang transform: method and its applications to geophysical studies. Reviews of Geophysics, 46: RG2006.

Hurrell, J.W., 1995. Decadal trends in the North-Atlantic oscillation - regional temperatures and precipitation. Science, 269(5224): 676-679.

Hurrell, J.W. and Deser, C., 2009. North Atlantic climate variability: The role of the North Atlantic Oscillation. Journal of Marine Systems, 78(1): 28-41.

Kaplan, A. et al., 1998. Analyses of global sea surface temperature 1856-1991. Journal of Geophysical Research-Oceans, 103(C9): 18567-18589.

Krueger, K.W. and Trappe, J.M., 1967. Food reserves and seasonal growth of Douglas-fir seedlings. Forest Science, 13(2): 192-\&.

Kushnir, Y., Seager, R., Ting, M., Naik, N. and Nakamura, J., 2010. Mechanisms of Tropical Atlantic SST Influence on North American Precipitation Variability. Journal of Climate, 23(21): 5610-5628.

Larocque, S.J. and Smith, D.J., 2005. A dendroclimatological reconstruction of climate since AD 1700 in the Mt. Waddington area, British Columbia Coast Mountains, Canada. Dendrochronologia, 22(2): 93-106.

Legendre, P. and Legendre, L. 1998. Numerical ecology, $2^{\text {nd }}$ Edition. Elsevier, Amsterdam, The Netherlands. $870 \mathrm{pp}$.

Lo, Y.-H., Blanco, J.A., Kimmins, J.P. 2010a. A word of caution when projecting future shifts of tree species ranges. The Forestry Chronicle, 86(3), 312-316.

Lo, Y.-H., Blanco, J.A., Seely, B., Welham, C. and Kimmins, J.P., 2010b. Relationships between climate and tree radial growth in interior British Columbia, Canada. Forest Ecology and Management, 259(5): 932-942.

Lo, Y.-H., Blanco, J.A., Seely, B., Welham, C. and Kimmins, J.P., 2011. Generating reliable meteorological data in mountainous areas with scarce presence of weather records: The performance of MTCLIM in interior British Columbia, Canada. Environmental Modelling \& Software, 26(5): 644-657.

MacDonald, G. M., and Case R. A. 2005. Variations in the Pacific Decadal Oscillation over the past millennium. Geophysical Research Letters, 32 (L087034), doi:10.1029/2005GL022478.

Mann, M.E. and Lees, J.M., 1996. Robust estimation of background noise and signal detection in climatic time series. Climatic Change, 33(3): 409-445.

McCabe, G.J. and Dettinger, M.D., 1999. Decadal variations in the strength of ENSO teleconnections with precipitation in the western United States. International Journal of Climatology, 19(13): 1399-1410.

McCabe, G.J., Palecki, M.A. and Betancourt, J.L., 2004. Pacific and Atlantic Ocean influences on multidecadal drought frequency in the United States. Proceedings of the National Academy of Sciences of the United States of America, 101(12): 4136-4141.

Moore, R.D. and McKendry, I.G., 1996. Spring snowpack anomaly patterns and winter climatic variability, British Columbia, Canada. Water Resources Research, 32(3): 623-632.

Mote, P.W., 2006. Climate-driven variability and trends in mountain snowpack in western North America. Journal of Climate, 19(23): 6209-6220. 
Mote, P.W., Canning, D.J., Fluharty, D.L., Francis, R.C., Franklin, J.F., Hamlet, A.F., Hershman, M., Holmberg, M., Ideker, K.N., Keeton, W.S., Lettenmaier, D.P., Leung, L.R., Mantua, N.J., Miles, E.L., Noble, B., Parandvash, H., Peterson, D.W., Snover, A.K. and Willard, S.R., 1999. Impacts of Climate Variability and Change, Pacific Northwest. U.S. Global Change Research Program, JISAO/SMA Climate Impacts Group University of Washington, Report of the Pacific Northwest Regional Assessment Group., Seattle, WA, 110 pp.

Nott, M.P., Desante, D.F., Siegel, R.B. and Pyle, P., 2002. Influences of the El Niño/Southern Oscillation and the North Atlantic Oscillation on avian productivity in forests of the Pacific Northwest of North America. Global Ecology and Biogeography, 11(4): 333-342.

Oglesby, R.J. and Erickson, D.J., 1989. Soil-moisture and the persistence of North-American drought. Journal of Climate, 2(11): 1362-1380.

Perez-Valdivia, C. and Sauchyn, D., 2011. Tree-ring reconstruction of groundwater levels in Alberta, Canada: Long term hydroclimatic variability. Dendrochronologia, 29(1): 41-47.

Pojar, J., Klinka, K. and Meidinger, D.V., 1987. Biogeoclimatic ecosystem classification in British Columbia. Forest Ecology and Management, 22(1-2): 119-154.

Rahim, K.J., 2014. Applications of Multitaper Spectral analysis to Nonstationary Data. Appendix A Multitaper R Package., Queen`s University, Kingston, ON, 210 pp.

Rayner, N.A., Parker, D.E., Horton, E.B., Folland, C.K., Alexander, L.V., Rowell, D.P., Kent, E.C. and Kaplan, A., 2003. Global analyses of sea surface temperature, sea ice, and night marine air temperature since the late nineteenth century. Journal of Geophysical Research-Atmospheres, 108(D14): 4407-4444.

Redmond, K.T. and Koch, R.W., 1991. Surface climate and streamflow variability in the Western United-States and their relationship to large-scale circulation indexes. Water Resources Research, 27(9): 2381-2399.

Rodwell, M.J., Rowell, D.P. and Folland, C.K., 1999. Oceanic forcing of the wintertime North Atlantic Oscillation and European climate. Nature, 398(6725): 320-323.

Shi, F., Li, J. and Wilson, R.J.S., 2014. A tree-ring reconstruction of the South Asian summer monsoon index over the past millennium. Sci. Rep., 4: 6739.

Shi, F., Yang, B., von Gunten, L., Qin, C. and Wang, Z., 2012. Ensemble empirical mode decomposition for tree-ring climate reconstructions. Theoretical and Applied Climatology, 109(1-2): 233-243.

Swain, L.G. and Eng, P., 1982. Evaluation of storm drainage from highway 97 otf Okanagan Lake at Kelowna, B.C. B.C. Ministry of Environment, Victoria, BC, 34 pp.

Thompson, D.W.J. and Wallace, J.M., 2001. Regional climate impacts of the Northern Hemisphere annular mode. Science, 293(5527): 85-89.

Trouet, V. et al., 2009. Persistent Positive North Atlantic Oscillation Mode Dominated the Medieval Climate Anomaly. Science, 324(5923): 78-80.

Trouet, V. and Van Oldenborgh G.J. 2013. KNMI Climate Explorer. a web-based research tool for high-resolution paleoclimatology. Tree-Ring Research, 69(1): 3-13.

Watson, E. and Luckman, B.H., 2001. Dendroclimatic reconstruction of precipitation for sites in the southern Canadian Rockies. Holocene, 11(2): 203-213. 
Watson, E. and Luckman, B.H., 2005. Spatial patterns of preinstrumental moisture variability in the southern Canadian Cordillera. Journal of Climate, 18(15): 2847-2863.

Wright, W.E. et al., 2015. Reconstruction of the springtime East Asian Subtropical Jet and Western Pacific pattern from a millennial-length Taiwanese tree-ring chronology. Climate Dynamics, 44(5-6): 1645-1659.

Wu, Z. and Huang, N.E., 2009. Ensemble empirical mode decomposition: a noise-assisted data analysis method. Advances in Adaptive Data Analysis, 1(01): 1-41.

Wu, Z., Huang, N.E., Long, S.R. and Peng, C.-K., 2007. On the trend, detrending, and variability of nonlinear and nonstationary time series. Proceedings of the National Academy of Sciences of the United States of America, 104(38): 14889-14894.

Wu, Z. et al., 2008. The modulated annual cycle: an alternative reference frame for climate anomalies. Climate Dynamics, 31(7-8): 823-841.

Zhang, Q.B., Alfaro, R.I. and Hebda, R.J., 1999. Dendroecological studies of tree growth, climate and spruce beetle outbreaks in Central British Columbia, Canada. Forest Ecology and Management, 121(3): 215-225.

Zhang, Q.B. and Hebda, R.J., 2004. Variation in radial growth patterns of Pseudotsuga menziesii on the central coast of British Columbia, Canada. Canadian Journal of Forest Research, 34(9): 1946-1954.

Zhang, X. and Chen, Z., 2016. A new method to remove the tree growth trend based on ensemble empirical mode decomposition. Trees, in press, doi:10.1007/s00468-015-1295-z.

Zhang, Z.-Z., Lin, Z.-S., Du, J.-L., Liu, H.-Y. and Yang, C., 2008. Analysis of the precipitation in Hokkaido Island over 50 years and its southern oscillation based on Empirical Mode Decomposition method. . Journal of Anhui Agricultural Sciences, 36(24): 10562-10564.

Zuur, A.F., Ieno, E.N. and Smith G.M., 2007. Analysing ecological data. Springer, New York. 624 p. 
Figure legends

Figure 1.Left panel: Position of the study site in relationship to the main oceans around North America. Right panel: Climate of Westwold (1950 - 2003). Dashed line: mean monthly precipitation including snow; Solid line: mean monthly temperature; y: number of years considered; T: mean annual temperature $\left({ }^{\circ} \mathrm{C}\right) ; \mathrm{P}$ : mean annual amount of precipitation $(\mathrm{mm}) ; \mathrm{T}_{\mathrm{M}}$ : absolute maximum temperature $\left({ }^{\circ} \mathrm{C}\right) ; \mathrm{t}_{\mathrm{M}}$ : mean daily maximum temperature $\left({ }^{\circ} \mathrm{C}\right) ; \mathrm{t}_{\mathrm{m}}$ : mean daily minimum temperature $\left({ }^{\circ} \mathrm{C}\right) ; \mathrm{T}_{\mathrm{m}}:$ absolute minimum temperature $\left({ }^{\circ} \mathrm{C}\right)$. Oblique striped area shows months with an absolute minimum temperature below $0{ }^{\circ} \mathrm{C}$ (frost period).

Figure 2. Time series plots of Westowold's average annual temperature, annual accumulated precipitation, and average annual indices of PDO, NIÑO12 and NAO. Lines show 5-year running average.

Figure 3. Annual tree ring growth index and its decomposition into five different IMFs and a residual non-IMF trend. In red, the two DGIs (DGI-1 is IMF 2 and DGI-2 is the sum of IMF 3 plus IMF 4).

Figure 4. Correlations between the detrended HadlSST1 sea surface temperature (SST) field and Westwold's (a) average spring temperature (March to May); (b) average summer temperature (July to September); (c) accumulated spring precipitation (March to May); (d) accumulated summer precipitation (July to September). Only correlations with $p<0.1$ are shown. The inverted blue triangle indicates Westowold's situation.

Figure 5. Cross-correlations between the growing indices (DGI-1 and DGI-2) and three monthly climate indices (NAO, PDO and NIÑO12) for different lags (in years, with climate indices leading). Red bars indicate significant correlations ( $p<0.05$ ), with values above the bars indicating the highest Pearson's $r$ coefficient for each variable.

Figure 6. Correlations between the two growth indices (DGIs) and the detrended HadlSST1 sea surface temperature (SST) field. (a) DGI-1 and the averaged March $_{\mathrm{t}-3}$ to June $\mathrm{t}_{\mathrm{t}-3}$ SST, and (b) DGI-2 and the averaged June $_{\mathrm{t}-3}$ to September $\mathrm{t}_{-3} \mathrm{SST}$. Only correlations with $p<0.1$ are shown. The inverted blue triangle indicates Westowold's situation. 


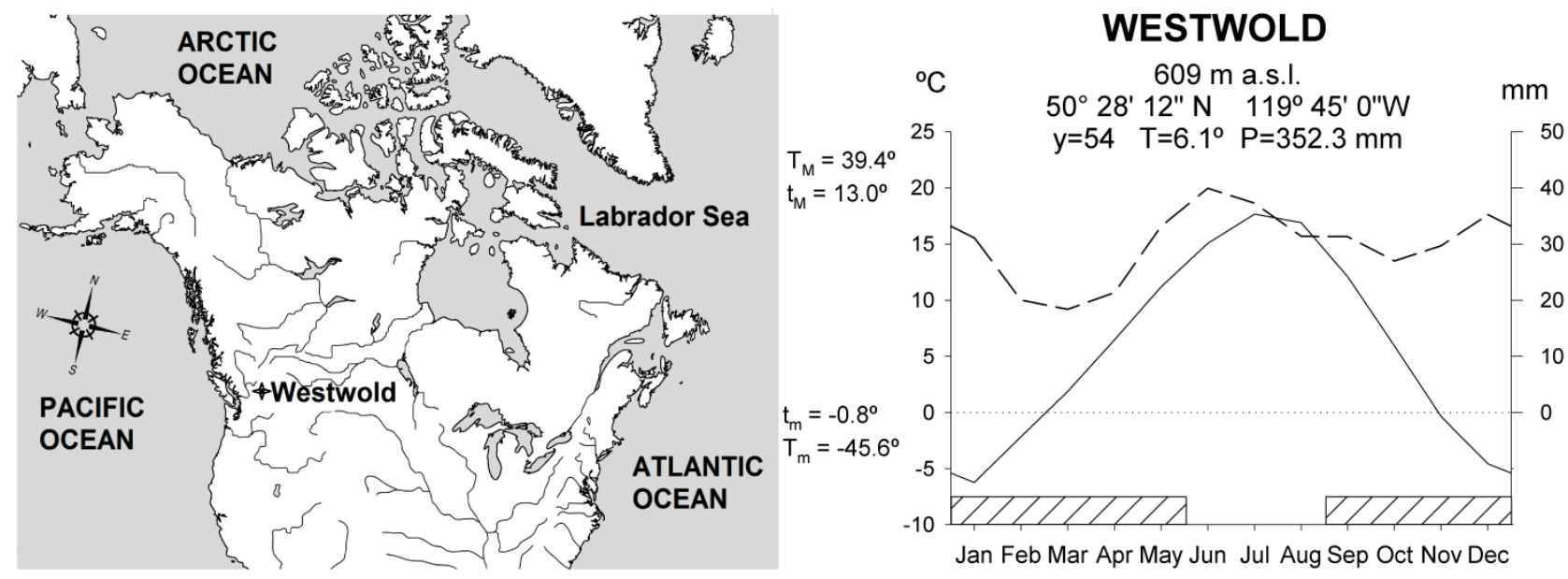

Figure 1. 


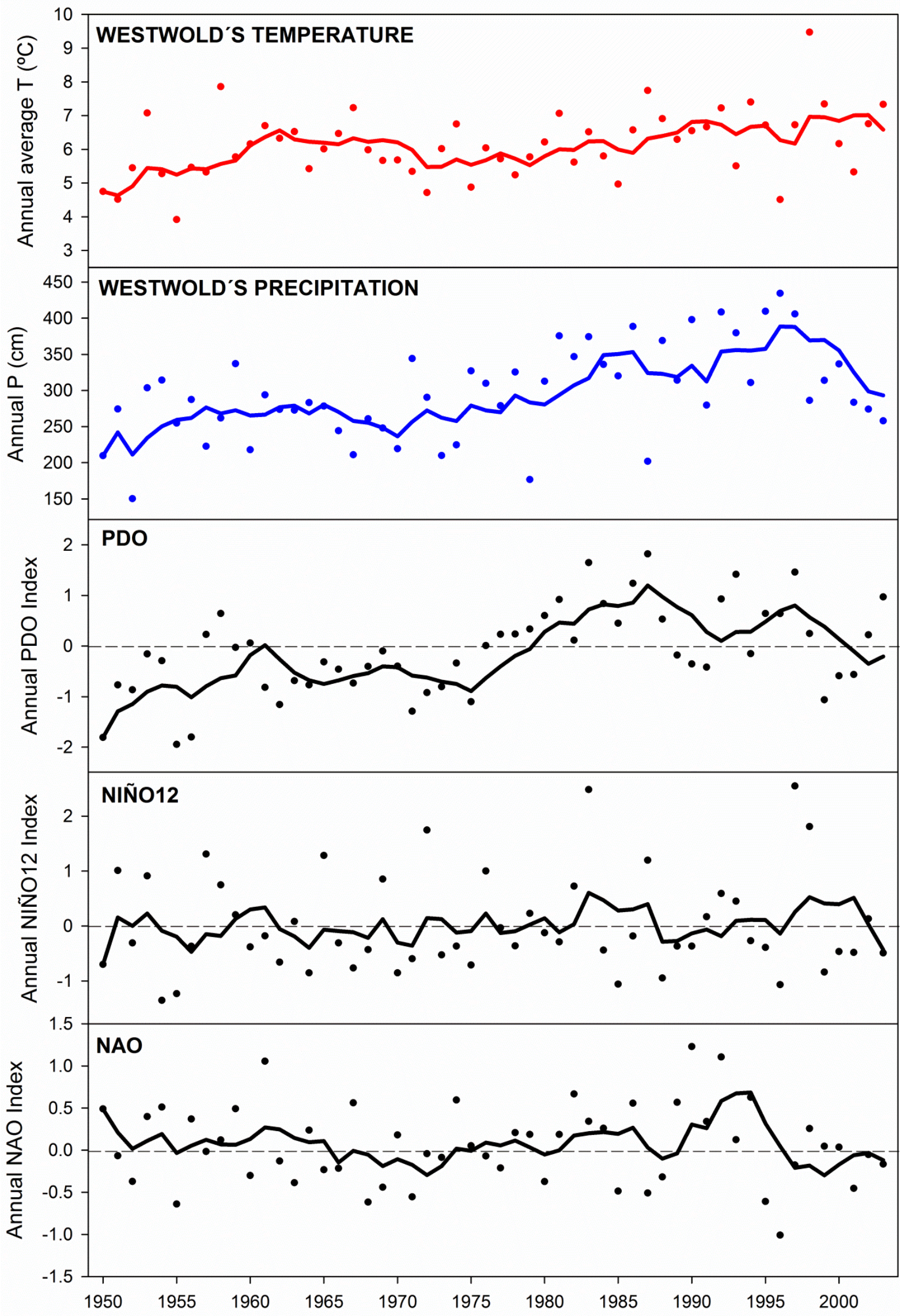

Figure 2. 

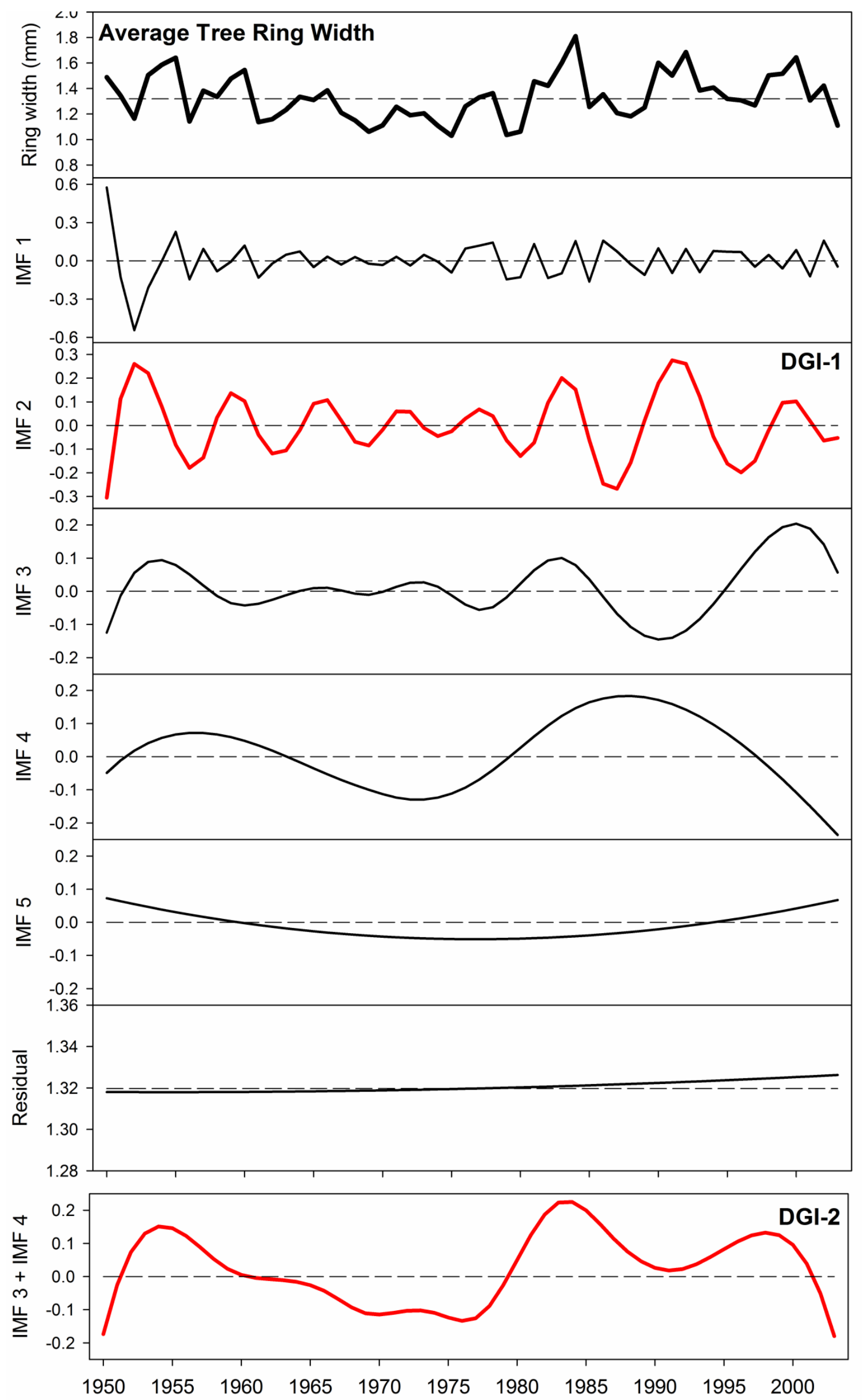

Figure 3. 

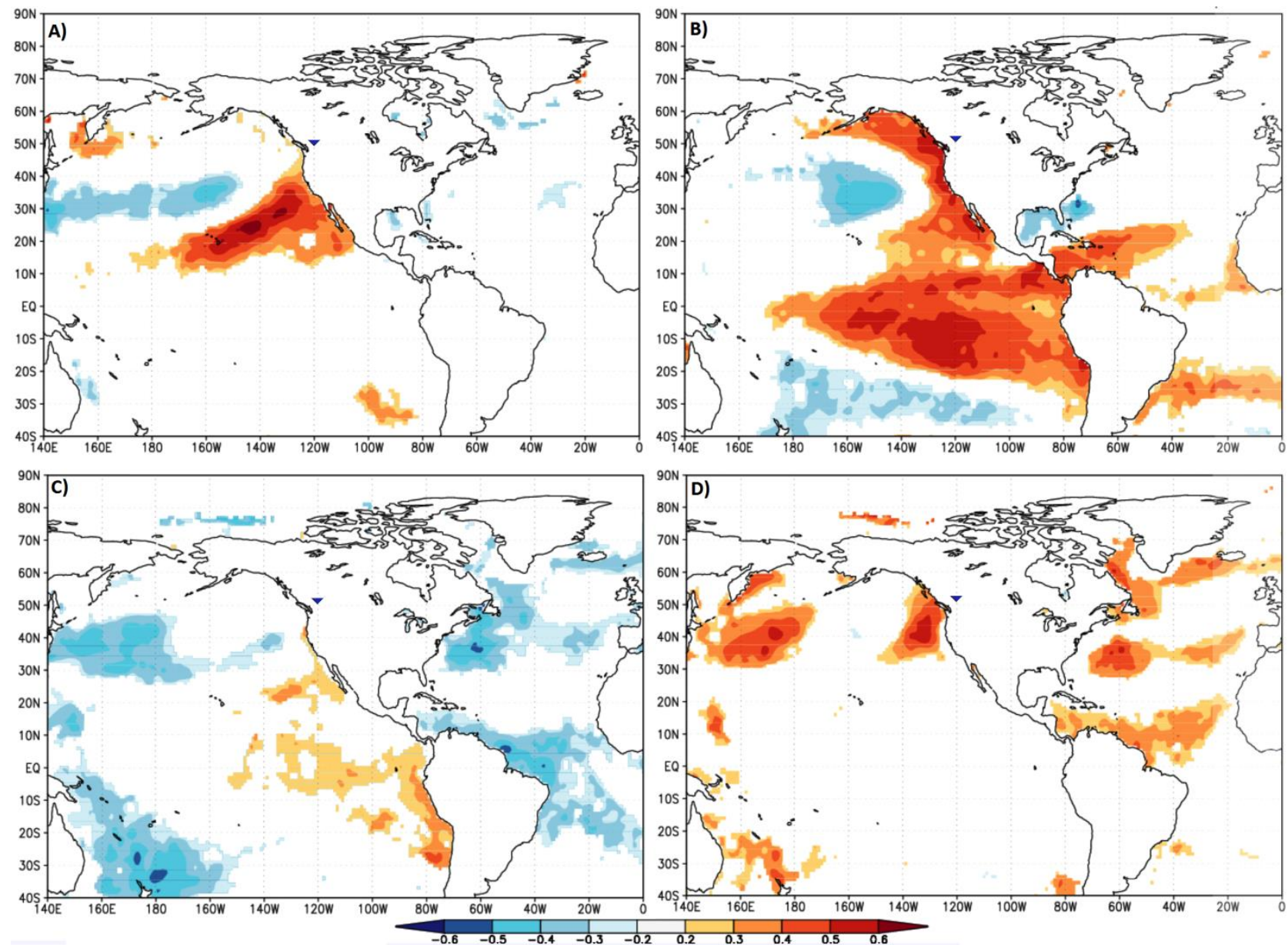

Figure 4. 


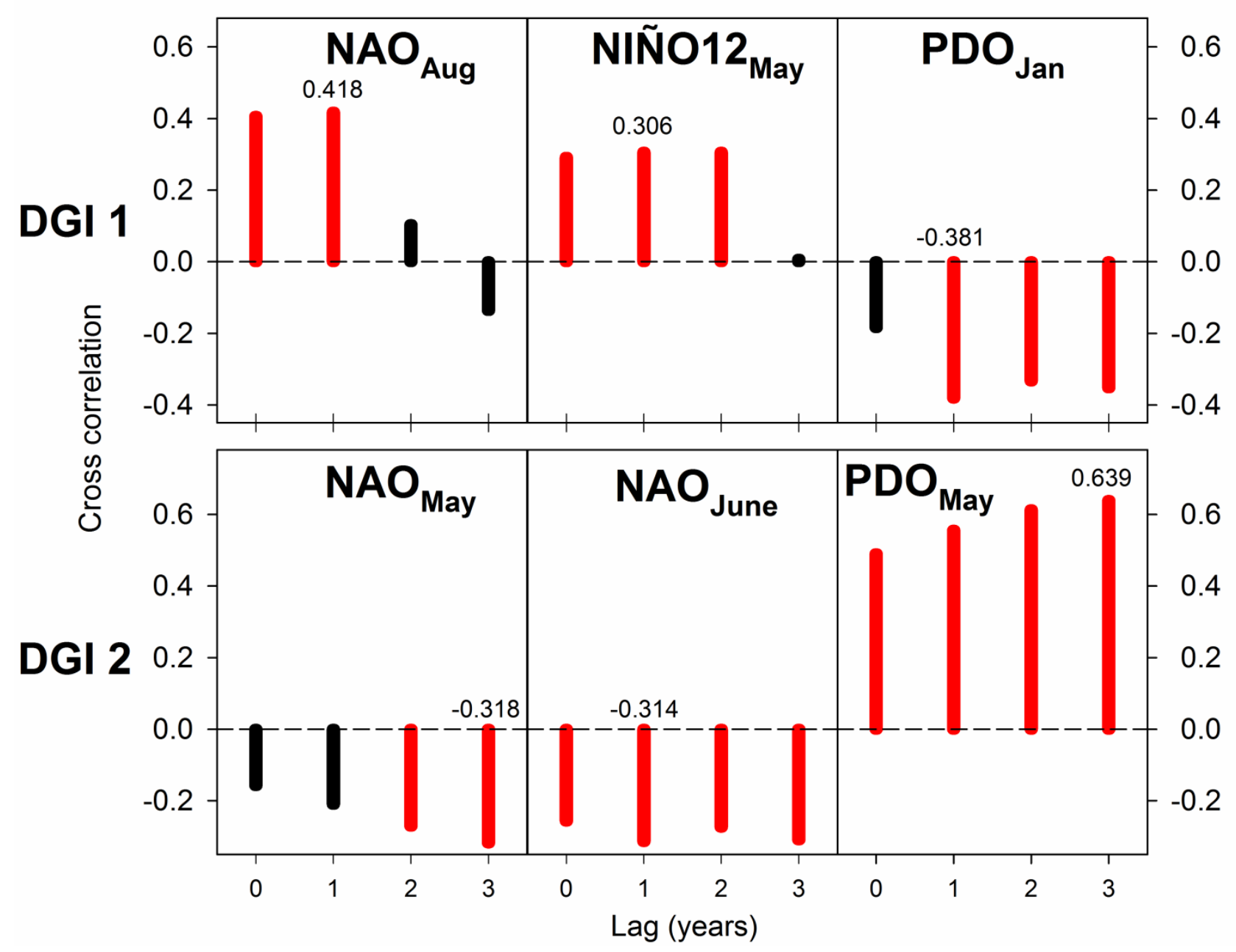

Figure 5. 

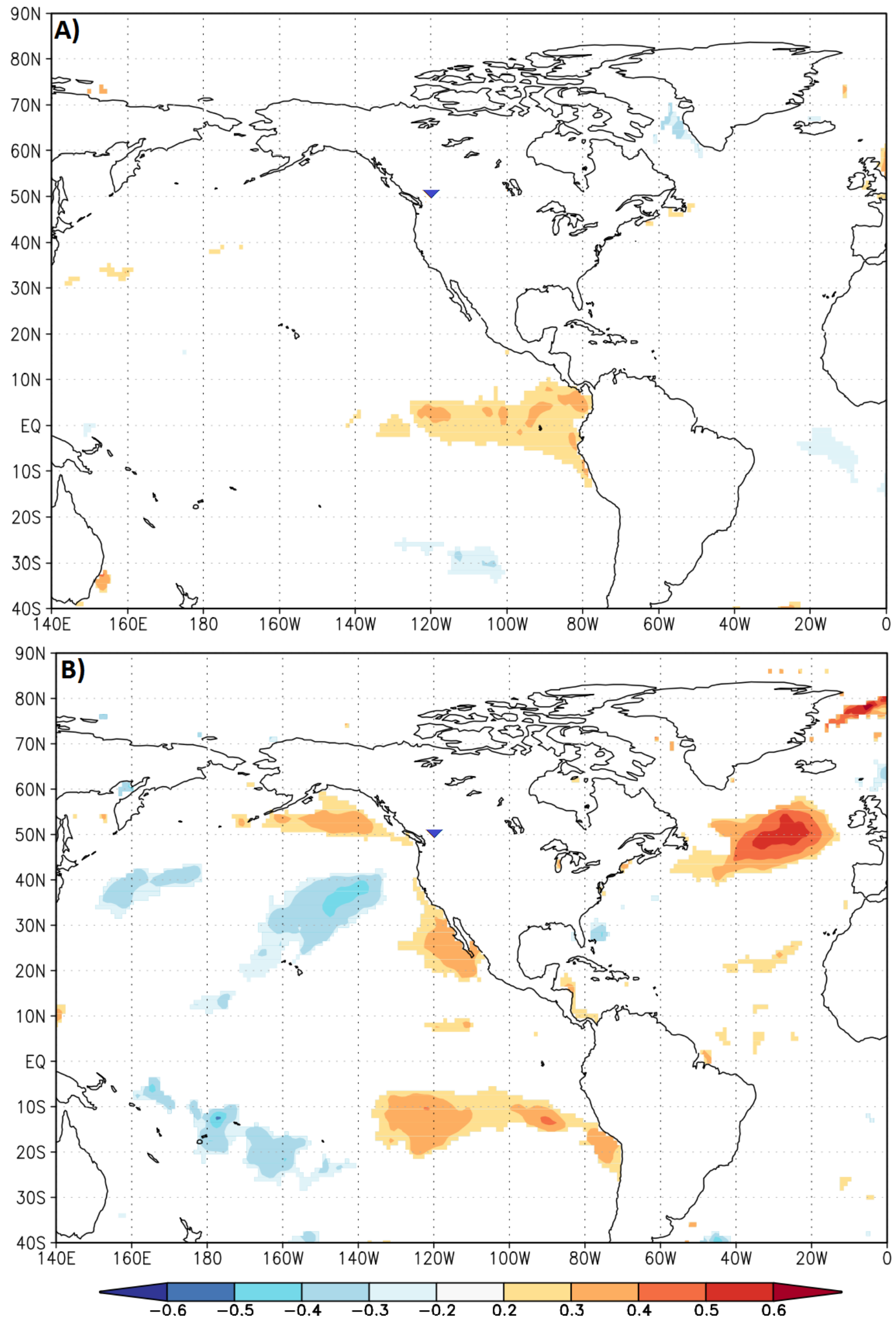

Figure 6. 